\title{
Complementary transcriptomic, lipidomic, and targeted functional genetic analyses in cultured Drosophila cells highlight the role of glycerophospholipid metabolism in Flock House virus RNA replication
}

\author{
Kathryn M Castorena ${ }^{1 \dagger}$, Kenneth A Stapleford ${ }^{3,4 \dagger}$, David J Miller ${ }^{1,2,3^{*}}$
}

\begin{abstract}
Background: Cellular membranes are crucial host components utilized by positive-strand RNA viruses for replication of their genomes. Published studies have suggested that the synthesis and distribution of membrane lipids are particularly important for the assembly and function of positive-strand RNA virus replication complexes. However, the impact of specific lipid metabolism pathways in this process have not been well defined, nor have potential changes in lipid expression associated with positive-strand RNA virus replication been examined in detail.

Results: In this study we used parallel and complementary global and targeted approaches to examine the impact of lipid metabolism on the replication of the well-studied model alphanodavirus Flock House virus (FHV). We found that FHV RNA replication in cultured Drosophila S2 cells stimulated the transcriptional upregulation of several lipid metabolism genes, and was also associated with increased phosphatidylcholine accumulation with preferential increases in lipid molecules with longer and unsaturated acyl chains. Furthermore, targeted RNA interferencemediated downregulation of candidate glycerophospholipid metabolism genes revealed a functional role of several genes in virus replication. In particular, we found that downregulation of Cct1 or Cct2, which encode essential enzymes for phosphatidylcholine biosynthesis, suppressed FHV RNA replication.

Conclusion: These results indicate that glycerophospholipid metabolism, and in particular phosphatidylcholine biosynthesis, plays an important role in FHV RNA replication. Furthermore, they provide a framework in which to further explore the impact of specific steps in lipid metabolism on FHV replication, and potentially identify novel cellular targets for the development of drugs to inhibit positive-strand RNA viruses.
\end{abstract}

\section{Background}

The relatively small genome of most positive-strand RNA viruses compels these pathogens to use cellular machinery to complete their replication cycles. The search for these "host factors" utilized by positive-strand RNA viruses is at the forefront of virology research, due in part to the possibility that cellular proteins or processes may represent more stable drug targets or provide broader antiviral activity when disrupted [1]. One

\footnotetext{
* Correspondence: milldavi@umich.edu

† Contributed equally

'Departments of Internal Medicine, University of Michigan Medical School,
} Ann Arbor, MI 48109, USA diverse host factor that has been identified as crucial for positive-strand RNA virus replication are intracellular membranes [2-5]. Although viruses that contain a lipid envelope as a structural component clearly utilize cellular membranes to form infectious virions, all positivestrand RNA viruses, both enveloped and non-enveloped, also depend on host intracellular membranes for the assembly and function of the viral RNA replication complexes essential for genome amplification. The precise functions of cellular membranes in this process have not been fully defined, but may include: (i) serving as structural scaffolds for replication complex targeting and assembly; (ii) protecting viral RNA or replication 
intermediates from cellular antiviral defense responses; or (iii) providing essential protein or lipid cofactors for optimal viral enzymatic activities. These proposed functions are not mutually exclusive, and it is likely that cellular membranes and their constituent components play multiple roles in viral RNA replication.

To investigate the role of host factors in viral RNA replication we use Flock House virus (FHV), a versatile model virus and natural insect pathogen that assembles robust functional RNA replication complexes in yeast $[6,7]$, plant [8], mammalian [9], nematode [10], and insect cells [11]. This broad array of eukaryotic hosts that support FHV RNA replication suggests that cellular factors utilized by this virus are widely conserved. The FHV genome is bipartite, with two positive-sense RNA segments copackaged into a non-enveloped virion (Fig. 1A). The larger 3.1-kb genomic segment, RNA1, encodes protein A, the FHV RNA-dependent RNA polymerase, which is the only viral protein required for functional RNA replication complex assembly. FHV assembles its RNA replication complexes on mitochondrial outer membranes $[7,11]$, where they are targeted and anchored in part via an amino-proximal transmembrane domain present within protein A [12]. During RNA replication FHV produces a 0.4-kb subgenomic segment, RNA3, which encodes the RNA interference
(RNAi) suppressor protein B2. This viral counterdefense protein is required for maximal viral RNA synthesis in cells with an active RNAi antiviral system $[10,13]$. Since subgenomic RNA3, and hence protein B2, are produced only during active RNA replication, they serve as convenient and quantitative markers for FHV RNA replication complex activity. The smaller 1.4-kb genomic segment, RNA2, encodes the structural capsid protein precursor. The FHV capsid protein is required for infectious virion production but is dispensable for viral RNA replication, and therefore engineered self-replicating viral RNAs, termed replicons, need only contain FHV RNA1 (Figs. 1B and 1C).

Apart from the membrane localization of its viral RNA replication complexes, additional lines of evidence point to the importance of membranes, and in particular lipids, in FHV replication. Protein A is a lipid-binding protein with particular affinity for specific anionic phospholipids [14], which may mediate in part the protein A-membrane interactions required for replication complex assembly. FHV RNA replication induces dramatic mitochondrial membrane rearrangements $[7,11,15,16]$, reminiscent of structures seen with other positive-strand RNA viruses [2]. The fatty acid synthetase inhibitor cerulenin disrupts FHV RNA replication [17], consistent with the activity of this inhibitor on other positive-

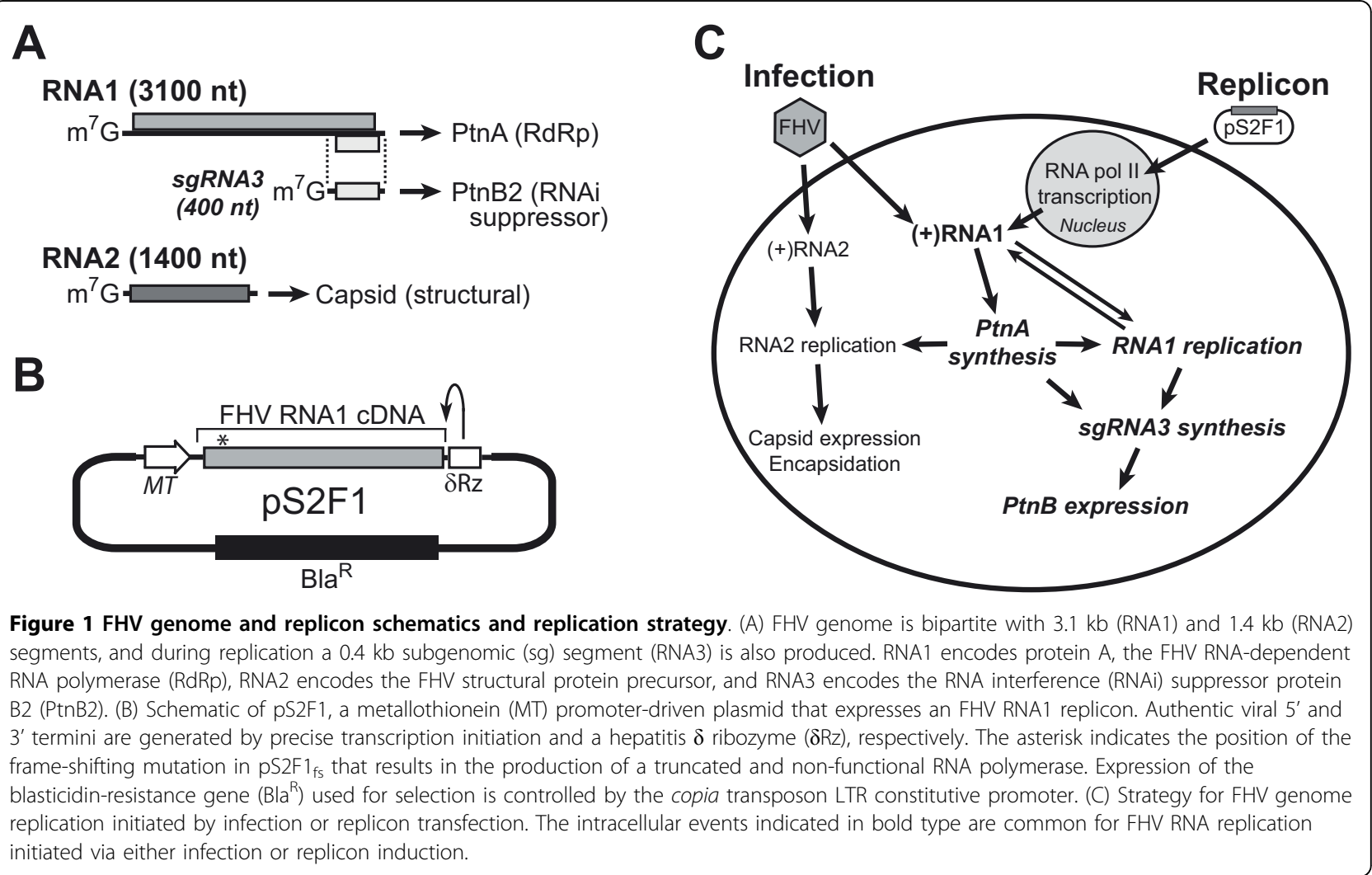


strand RNA viruses $[18,19]$. Finally, FHV RNA replication complex activity in isolated membrane fractions analyzed in vitro is disrupted by certain detergents [20], and can be augmented by the addition of exogenous phospholipids [21]. These results all suggest a central role of cellular lipid metabolism in FHV RNA replication complex assembly and function. However, none of them provide direct evidence for a functional impact of specific lipid metabolism pathways on FHV RNA replication within intact cells.

In this report, we use complementary transcriptomic, lipidomic, and targeted functional genetic analyses to specifically examine the role of lipids in FHV RNA replication in cultured Drosophila cells. We demonstrate that FHV infection or replicon expression upregulates the transcription of a distinct set of cellular genes, several of which are involved in lipid metabolism. Furthermore, FHV RNA replication induces global changes in cellular phospholipid content, and in particular phosphatidylcholine (PC), and pharmacologic or genetic disruption of PC synthesis within cells inhibits FHV RNA replication.

\section{Results}

FHV RNA replication induces transcriptional upregulation of lipid metabolism genes in Drosophila S2 cells

We examined the transcriptional responses of Drosophila S2 cells to FHV RNA replication using genomewide microarray analyses. To focus on cellular responses related to RNA replication rather than those associated with other steps in the viral life cycle, such as virion attachment, entry, uncoating, encapsidation, and virion release, we conducted parallel analyses of cells either infected with FHV or transfected with an RNA1 replicon-expression plasmid. The RNA1 segment of the FHV genome encodes the viral RNA-dependent RNA polymerase (Fig. 1A) and is the only genome segment required for RNA replication (Fig. 1C). Thus, FHV RNA replication can be initiated in S2 cells by the introduction of a self-replicating RNA1 via the inducible plasmid pS2F1 (Figs. 1B and 1C) [22]. To maximize the number of S2 cells expressing the replicon, we first generated stable cell lines containing pS2F1 or a control plasmid $\left(\mathrm{pS} 2 \mathrm{~F} 1_{\mathrm{fs}}\right.$, see Fig. 1B legend) containing a translationdefective RNA1 segment. Although there was a low level of baseline FHV RNA replication in pS2F1-expressing cells due to leaky metallothionein promoter activity, induction with copper sulfate resulted in a dramatic increase in subgenomic RNA3 and protein B2 accumulation, indicative of highly active viral RNA replication complexes (data not shown).

We analyzed transcript levels from three independent experiments with either FHV-infected cells or cells expressing an RNA1 replicon, and identified cellular genes whose transcription was significantly up- or downregulated in response to these stimuli. We identified 790 genes that were significantly upregulated and 392 genes that were significantly downregulated in FHV-infected S2 cells (Additional File 1), and 305 genes that were significantly upregulated in pS2F1-expressing cells (Additional File 2). There were no significantly downregulated genes in pS2F1-expressing cells. Full details regarding the molecular functions, biological processes, and cellular components for these genes are provided in the additional files. We further analyzed these datasets for transcripts that were upregulated with both stimuli and identified 73 co-regulated genes, which encoded proteins involved in numerous aspects of cellular physiology, such as metabolism, defense responses, and signal transduction (Table 1 and Additional File 3). Based in part on the well recognized importance of cellular membranes in positive-strand RNA virus replication [3-5], we focused on those genes that encoded proteins with known or hypothesized roles in lipid metabolism. We found that infection with FHV upregulated eight lipid metabolism-associated genes, whereas RNA1 replicon expression upregulated thirteen lipid metabolism-associated genes (Fig. 2A). Four of these genes were upregulated in both datasets, including Cct1 and $C c t 2$, which encode CTP:phosphocholine cytidylyltransferases. These enzymes are essential for the salvage pathway of PC synthesis but have non-overlapping functions in Drosophila cells [23-26]. We validated both Cct 1 and Cct 2 mRNA upregulation by RT-PCR after FHV infection (Fig. 2B) and RNA1 replicon expression (Fig. 2C). These results demonstrated that FHV RNA replication in Drosophila S2 cells was associated with distinct alterations in cellular gene transcription, including the transcription of genes associated with lipid metabolism.

\section{FHV RNA replication alters phospholipid levels in Drosophila S2 cells}

The conclusion that FHV RNA replication was associated with transcriptional upregulation of lipid metabolism genes predicts that quantifiable changes in lipid constituents should also be observed, particularly with respect to $\mathrm{PC}$ content. To examine this prediction we measured total PC levels in S2 cells after infection or replicon expression using a modified phospholipase Dbased biochemical assay [27] (Fig. 3A). As a control for these experiments we used cells treated with 1-hexadecylphosphorylcholine (miltefosine), which is a specific CTP:phosphocholine cytidylyltransferase inhibitor [28]. S2 cells infected with FHV had a 35\% increase in total PC levels, whereas treatment with miltefosine reduced PC levels by $40 \%$ (Fig. 3A, left graph). Furthermore, although baseline PC levels in stably transfected cells 
Table 1 Drosophila genes co-upregulated in $\mathbf{S 2}$ cells either infected with FHV or expressing an RNA1 replicon.

\begin{tabular}{|c|c|c|}
\hline Biological Process & $\begin{array}{c}\text { Gene } \\
\text { Symbol }\end{array}$ & Gene Name \\
\hline \multirow{2}{*}{$\begin{array}{l}\text { Carbohydrate } \\
\text { metabolism }\end{array}$} & cenB1A & Centaurin $\beta 1 \mathrm{~A}$ \\
\hline & CG12582 & - \\
\hline \multirow[t]{2}{*}{ Heme metabolism } & Alas & Aminolevulinate synthase \\
\hline & I(3)02640 & Lethal (3) 02649 \\
\hline \multirow[t]{4}{*}{ Lipid metabolism } & Cct1 & $\begin{array}{l}\text { CTP:phosphocholine } \\
\text { cytidylyltransferase } 1\end{array}$ \\
\hline & Cct2 & $\begin{array}{l}\text { CTP:phosphocholine } \\
\text { cytidylyltransferase } 2\end{array}$ \\
\hline & CG3902 & - \\
\hline & Lip4 & Lipase 4 \\
\hline \multirow[t]{7}{*}{ Protein metabolism } & CalpC & Calpain C \\
\hline & CG1340 & - \\
\hline & CG4266 & - \\
\hline & CG18557 & - \\
\hline & dream & dream \\
\hline & pUf68 & Poly U binding factor $68 \mathrm{kDa}$ \\
\hline & stv & Starvin \\
\hline \multirow[t]{4}{*}{ Metabolism, other } & CG3168 & - \\
\hline & CG9886 & - \\
\hline & CG10137 & - \\
\hline & CG17807 & - \\
\hline \multirow[t]{7}{*}{ Defense response } & cactin & cactin \\
\hline & dos & Daughter of sevenless \\
\hline & Eip75B & Ecdysone-induced protein 75B \\
\hline & PGRP-LA & $\begin{array}{c}\text { Peptidoglycan recognition protein } \\
\text { LA }\end{array}$ \\
\hline & Rel & Relish \\
\hline & Sp7 & Serine protease 7 \\
\hline & Traf-like & TNF-receptor-associated factor-like \\
\hline \multirow[t]{9}{*}{ Signal transduction } & CG6954 & - \\
\hline & CG11534 & - \\
\hline & CG12091 & - \\
\hline & Dgp-1 & Dgp-1 \\
\hline & drongo & drongo \\
\hline & Ptp61f & Protein tyrosine phosphatase $61 \mathrm{~F}$ \\
\hline & RhoGAP18B & RhoGAP18B \\
\hline & Socs36E & $\begin{array}{l}\text { Suppressor of cytokine signalling } \\
\text { at } 36 \mathrm{E}\end{array}$ \\
\hline & sra & Sarah \\
\hline \multirow[t]{4}{*}{ Transcription } & CG16903 & - \\
\hline & Ets21C & Ets at $21 \mathrm{C}$ \\
\hline & Nvy & Nervy \\
\hline & Rab10 & Rab-protein 10 \\
\hline \multirow{2}{*}{$\begin{array}{l}\text { Cytoskeletal } \\
\text { organization }\end{array}$} & Insc & Inscuteable \\
\hline & WASp & WASp \\
\hline
\end{tabular}

Table 1: Drosophila genes co-upregulated in S2 cells either infected with FHV or expressing an RNA1 replicon. (Continued)

\begin{tabular}{|c|c|c|}
\hline \multirow[t]{2}{*}{ Transport } & CG4726 & - \\
\hline & Tamo & tamo \\
\hline DNA synthesis & DNApol-iota & DNApol-iota \\
\hline Stress response & Hsp23 & Heat shock protein 23 \\
\hline Cell development & Foi & Fear-of-intimacy \\
\hline Ubiquitin cycle & CG9153 & - \\
\hline \multirow[t]{25}{*}{ Unknown } & CG1529 & - \\
\hline & CG4036 & - \\
\hline & CG4281 & - \\
\hline & CG5118 & - \\
\hline & CG5399 & - \\
\hline & CG6701 & - \\
\hline & CG6762 & - \\
\hline & CG7326 & - \\
\hline & CG7457 & - \\
\hline & CG7967 & - \\
\hline & CG8620 & - \\
\hline & CG9796 & - \\
\hline & CG12022 & - \\
\hline & CG12084 & - \\
\hline & CG13117 & - \\
\hline & CG13917 & - \\
\hline & CG13926 & - \\
\hline & CG14642 & - \\
\hline & CG33191 & - \\
\hline & CG34349 & - \\
\hline & CG42324 & \\
\hline & Cyp6a17 & Сурба17 \\
\hline & meso18E & meso18E \\
\hline & Msr-110 & Msr-110 \\
\hline & unc-119 & unc-119 \\
\hline
\end{tabular}

Biological process designation was determined from either direct GO biological process terms or inferred from GO molecular function terms curated from the Flybase database http://flybase.org/. Complete data for coupregulated genes, including Flybase ID, CCG number, gene symbol, gene name, GO terms (function, process, and compartment), genetic interaction partners, yeast and human orthologs, and fold change are provided as Additional File 3.

were increased compared to untransfected cells, expression of an FHV RNA1 replicon was associated with a $70 \%$ increase in PC levels (Fig. 3A, right graph). These results indicated that FHV RNA replication-associated transcriptional upregulation of PC biosynthetic genes in S2 cells (Fig. 2) was associated with a concomitant increase in cellular PC levels.

To evaluate potential lipid changes associated with FHV replication in S2 cells in more detail we used electrospray ionization tandem mass spectrometry (ESI-MS/ 


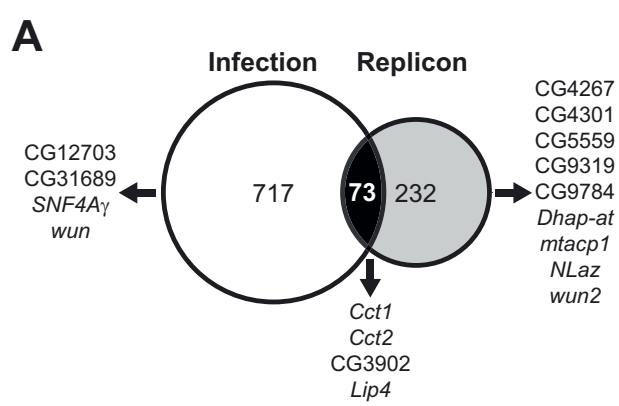

B

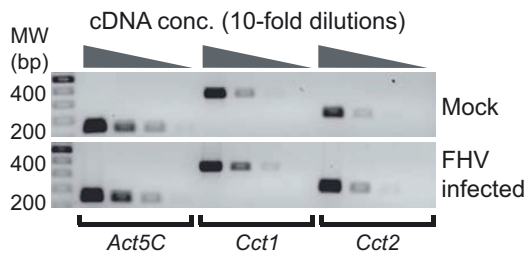

C

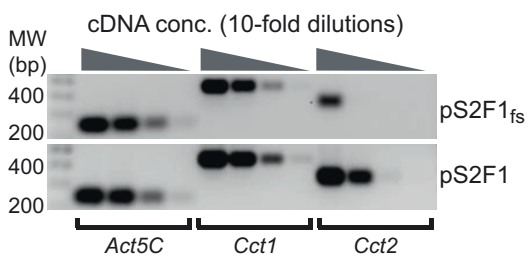

Figure 2 FHV infection and replicon expression upregulate partially overlapping sets of Drosophila genes. (A) Venn diagram indicating the number of upregulated genes unique to FHV-infected cells (white circle), unique to FHV replicon-expressing cells (grey circle), or upregulated with both (black convergence). Total numbers of genes are given within the indicated regions, and complete lists and descriptions of genes are provided in Table 1 and as Additional Files 1, 2 and 3. Specific upregulated genes involved in lipid metabolism, as identified by GO terms, are shown by either their gene symbols or CG designations. (B) Semiquantitative RT-PCR validation of Cct1 and Cct2 mRNA upregulation in Drosophila S2 cells infected with FHV. Decreasing amounts of CDNA generated by RT with oligo-dT primers and equivalent amounts of total RNA from mock (upper gel) or FHV-infected S2 cells (lower gel) were amplified with gene-specific primers for Drosophila actin (Act5C), Cct 1, or Cct2, and PCR products were examined by agarose gel electrophoresis and ethidium bromide staining. The expression level of the $A c t 5 C$ transcript in microarray experiments was not significantly altered with FHV infection or replicon expression. Densitometry analysis of PCR products generated from CDNA dilutions that produced submaximal signals showed that FHV infection induced $2.0 \pm 0.2$ and $2.3 \pm 0.3$ fold increases in Cct1 and Cct2 mRNA levels, respectively, consistent with quantitative microarray results (see Additional File 1). (C) Semiquantitative RT-PCR validation of Cct1 and Cct2 mRNA upregulation in Drosophila S2 cells expressing an FHV replicon. RT-PCR was performed as described above with total RNA from S2 cells containing the control plasmid $\mathrm{pS} 2 \mathrm{~F} 1_{\mathrm{fs}}$ (upper gel) or FHV repliconencoding plasmid pS2F1 (lower gel). Densitometry analysis of PCR products as described above showed that FHV replicon expression induced $1.9 \pm 0.2$ and $2.8 \pm 0.9$ fold increases in Cct1 and Cct2 mRNA levels, respectively, consistent with quantitative microarray results (see Additional File 2).
MS) to quantitate polar phospholipids in extracts from FHV-infected cells. This analysis allowed the determination of relative individual phospholipid species content as a molar percentage of total recovered polar phospholipids but also provided details on total acyl chain length and saturation levels. As controls for these experiments we used cells treated with miltefosine to decrease PC levels or cells cultured with $1 \mathrm{mM}$ oleic acid (cis-9-octadecenoic acid), which increases the production of phospholipids with individual C18:1 acyl chains and hence total sum acyl chain compositions of C36:2. Complete detailed results from the ESI-MS/MS analyses are provided in Additional File 4. Control membrane extracts from S2 cells contained predominantly PC and phosphatidylethanolamine (PE) as the primary phospholipids, with the latter representing the majority $(\sim 40 \%)$ of all phospholipids (Fig. 3B). Although PC is typically the most prominent phospholipid in most eukaryotic cell membranes, Diptera species such as Drosophila contain relatively high levels of PE [29]. As expected, miltefosine dramatically reduced PC content with compensatory increases in the percentages of PE and phosphatidylinositol (PI). In contrast, total cellular membranes from FHV-infected S2 cells showed a trend towards an increase in the molar percentage of $\mathrm{PC}$ and phosphatidylserine (PS) with an associated decrease in PE content, but these differences were not statistically significant (Fig. 3B). However, when we analyzed PC species based on total acyl chain length or saturation level there were modest but statistically significant changes in the percentage of PC molecules with total acyl chain lengths of 32 or 34 carbons (Fig. 3C) and 0, 1, or 2 total double bonds (Fig. 3D), where FHV infection increased the fraction of PC molecules with longer unsaturated acyl chains. Furthermore, the selective increase in longer unsaturated acyl chains in FHV-infected cells was seen specifically with PC and not PE, PI, or PS (Fig. 3E and data not shown). These quantitative lipid analysis results suggested that FHV infection induces selective changes in PC metabolism, and are consistent with the observation that FHV RNA replication complex activity in isolated membrane fractions analyzed in vitro is preferentially stimulated by phospholipids with increased acyl chain length and decreased saturation [21].

\section{Manipulation of glycerophospholipid metabolism gene expression modulates FHV RNA replication in Drosophila S2 cells}

We next examined the potential functional significance of lipid metabolism gene upregulation on FHV RNA replication in S2 cells using a targeted genetic approach that employed RNAi-mediated knockdown [17]. We identified thirty-one cDNAs within the O'Farrell RNAi collection [30] that were targeted toward genes involved 


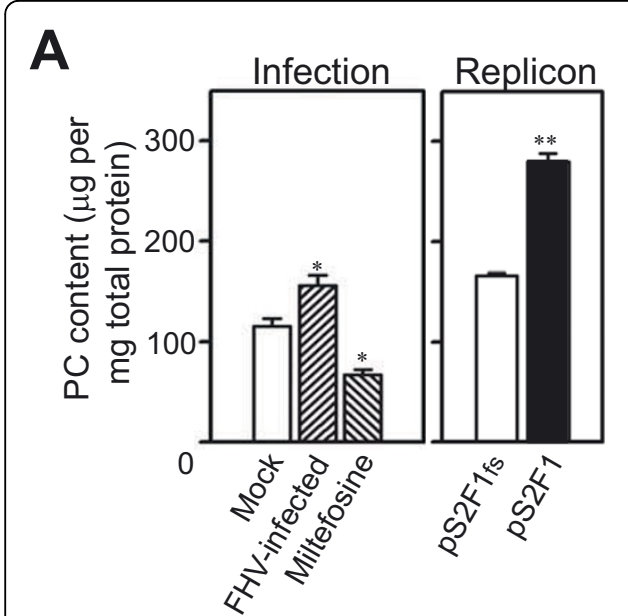

C

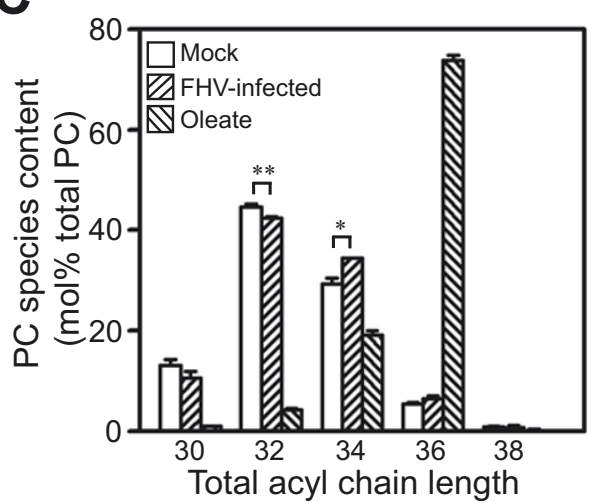

B

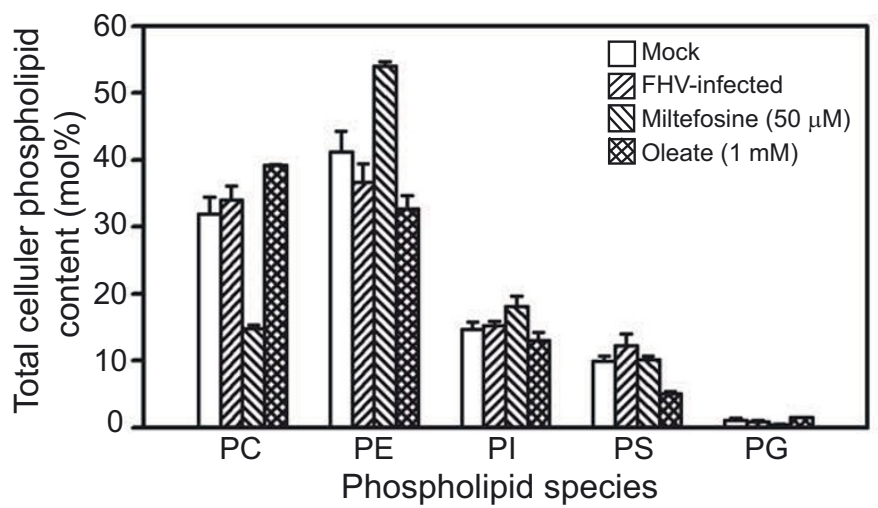

D

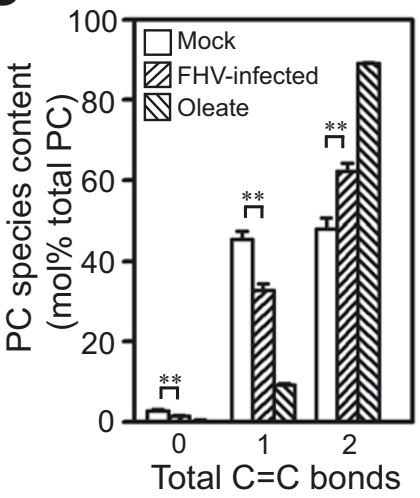

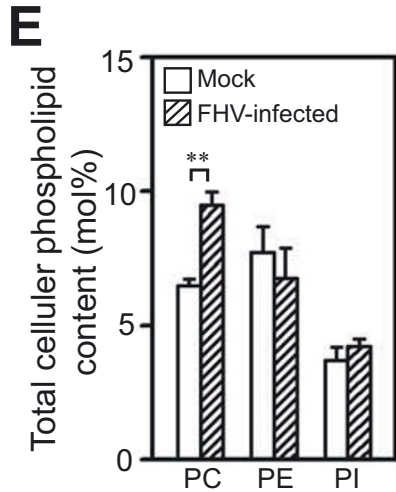

C34:2 phospholipids

Figure 3 FHV infection and replicon expression modulate phospholipid levels in Drosophila S2 cells. (A) Total PC levels in S2 cells infected with FHV or treated with miltefosine (left graph) or expressing an FHV RNA1 replicon (right graph). Total PC levels were determined in cells $24 \mathrm{~h}$ after infection, treatment, or replicon induction and are expressed relative to total cellular protein levels. (B) Phospholipid species distribution in control S2 cells, cells infected with FHV, or cells treated with miltefosine or oleic acid. Relative phospholipid species content is expressed as a molar percentage of total phospholipid content and was determined by ESI-MS/MS. (C) PC acyl chain length in mock, FHVinfected, and oleic acid-treated S2 cells. Total PC chain length was determined by ESI-MS/MS and represents the total number of carbons from both acyl chains. (D) PC acyl chain saturation in mock, FHV-infected, and oleic acid-treated S2 cells. Total number of C $=$ C double bonds in PC species was determined by ESI-MS/MS and represents the total number of double bonds in both acyl chains. The fraction of PC species with greater than two double bonds was 0.5 to $1.5 \%$ for both mock and FHV-infected cells (see Additional File 4), and therefore these results were not included in the graph. (E) PC, PE, and PI species with acyl chains containing a total of 34 carbons and 2 double bonds in mock and FHVinfected S2 cells. P-value $<0.05^{*}$ or $0.005^{* *}$.

in glycerophospholipid metabolism in Drosophila cells, generated 300-600 bp dsRNAs, and performed RNAi knockdown experiments with infected S2 cells using dsRNA targeted against FHV RNA1 and miltefosine as positive controls (Fig. 4A). To quantitate FHV RNA replication, we used an optimized capture enzymelinked immunosorbant assay (ELISA) that detected protein B2, which is a viral protein only produced during active RNA replication (see Fig. 1C). Although protein $\mathrm{B} 2$ is an RNAi suppressor, it functions during the assembly of RNAi-induced silencing complexes [31], and therefore would have less impact on the activity of functional silencing complexes formed during the $48 \mathrm{~h}$ dsRNA incubation period prior to FHV infection. We found that dsRNAs directed against five cellular genes,
Ace, Cct1, Cct2, fu12, and san, all significantly suppressed FHV RNA replication in infected S2 cells (Fig. $4 \mathrm{~A})$. Although the level of suppression was $20-40 \%$ with individual knockdown of these five genes, the positive control FHV dsRNA only reduced protein B2 levels by $\sim 45 \%$, suggesting that this medium throughput assay provided a conservative estimate of the functional impact of cellular glycerophospholipid metabolism gene knockdown. The functions of $C c t 1$ and $C c t 2$ have been described above. Ace encodes acetylcholine esterase [32], fu12 encodes an enzyme with 1-acylglycerol-3-phosphate acyltransferase activity [33], and san also encodes an enzyme with acyltransferase activity [34]. The enzymes encoded by Cct1, Cct2, Ace, fu12, and san are all involved in PC synthesis, either directly or indirectly 
A

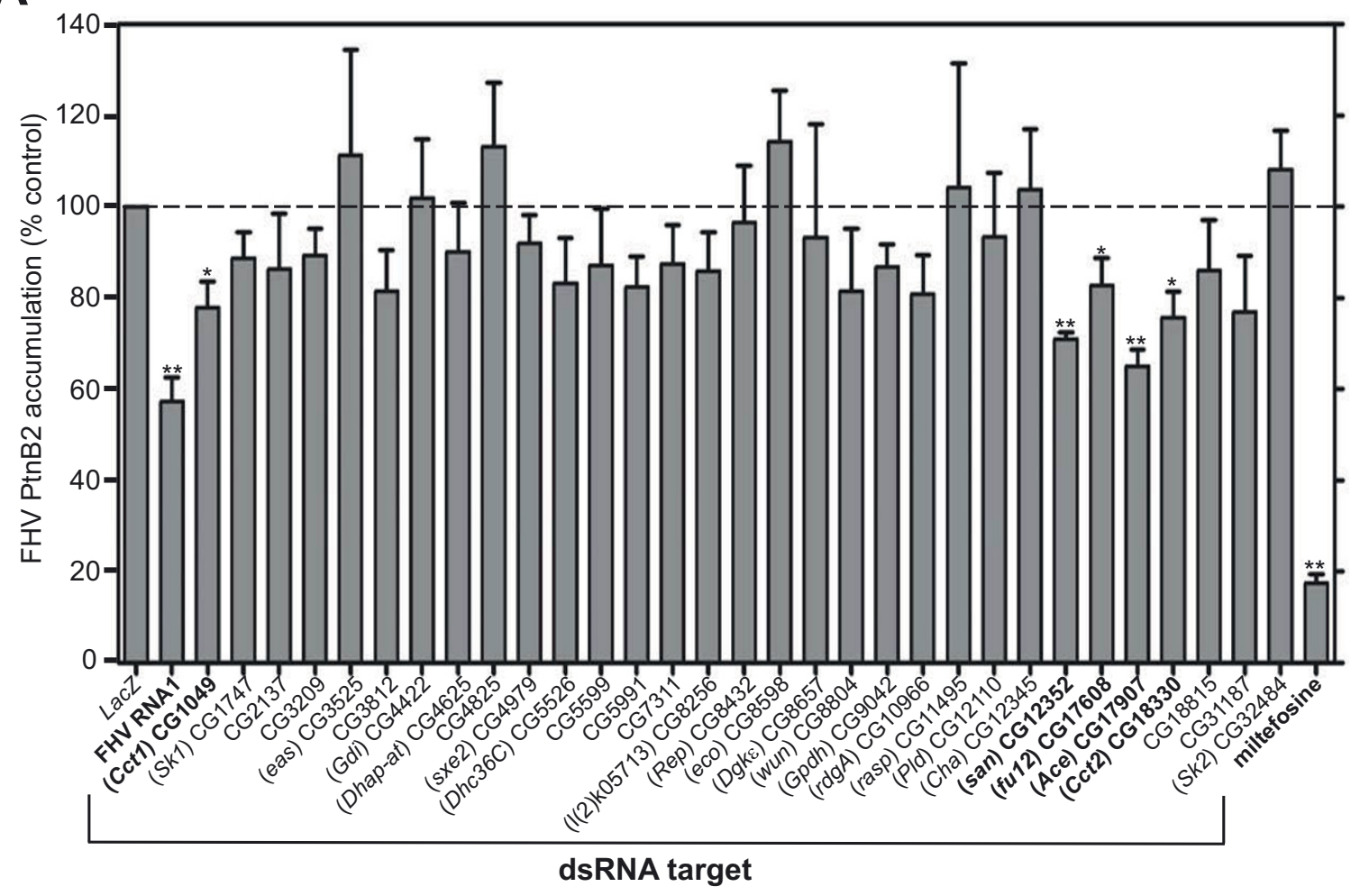

B

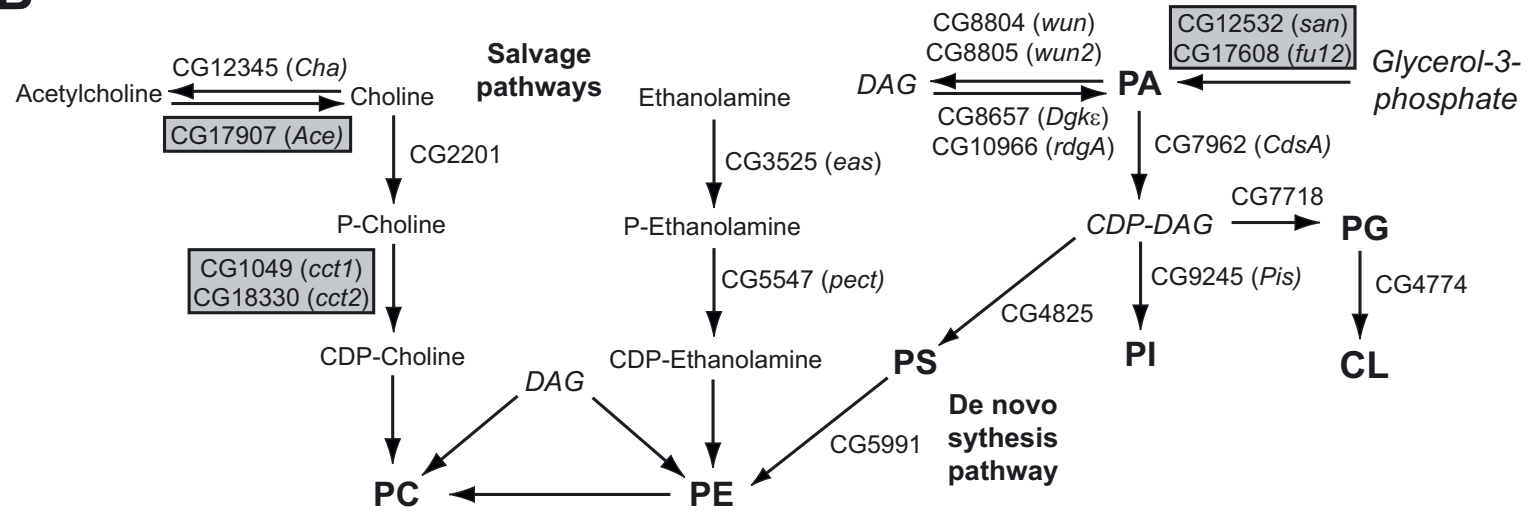

Figure 4 RNAi-mediated knockdown of Drosophila genes involved in glycerophospholipid metabolism modulate FHV replication in S2 cells. (A) Medium throughput RNAi-based functional screen of select glycerophospholipid metabolism genes. Drosophila S2 cells were cultured in 96-well plates, incubated with dsRNA targeting specific glycerophospholipid metabolism-related genes, positive control FHV RNA1, or negative control LacZ for $48 \mathrm{~h}$, infected with FHV, and harvested $18 \mathrm{~h}$ after infection. As an additional separate control, selected wells were treated with $50 \mu \mathrm{M}$ miltefosine at the time of infection. FHV replication was assayed by protein B2 (PtnB2)-specific capture ELISA. Parallel MTT viability assays demonstrated $>90 \%$ viability for all dsRNA- or miltefosine-treated samples compared to LacZ dsRNA-treated control (data not shown). Results are expressed as the percentage of PtnB2 accumulation relative to LacZ dsRNA-treated control (hatched line). $P$-value $<0.05^{*}$ or $0.005^{* *}$. (B) Schematic of eukaryotic glycerophospholipid synthesis pathways. The simplified biosynthetic pathways shown were adapted from the detailed and comprehensive KEGG glycerophospholipid metabolism pathway available at http://www.genome.jp/kegg/. Drosophila genes with known or hypothesized lipid biosynthetic functions are shown, and those identified as being functionally important for FHV RNA replication are boxed in grey. The major eukaryotic glycerophospholipids are indicated in bold type: CL, cardiolipin; PA, phosphatidic acid; PC, phosphatidylcholine; PE, phosphatidylethanolamine; PG, phosphatidylglycerol; PI, phosphatidylinositol; PS, phosphatidylserine. The essential precursor glycerol-3-phosphate and important intermediates are shown in italics: DAG, diacylglycerol. 
(Fig. 4B). The main glycerophospholipids in the cell, PC and $\mathrm{PE}$, are synthesized through two metabolic pathways, the de novo synthesis pathway that uses PS as a precursor for both, and the salvage or CDP pathway, also referred to as the Kennedy pathway, which recycles choline and ethanolamine to produce PC and PE, respectively [35]. In higher eukaryotes the salvage or CDP pathway of PC synthesis normally predominates, where the conversion of phosphocholine to CDP-choline, which is catalyzed by CTP:phosphocholine cytidylyltransferases such as those encoded by $C c t 1$ and $C c t 2$, is the rate limiting step [35]. Thus, we chose to focus further on these two Drosophila glycerophospholipid synthesis genes.

To verify the functional impact of Cct1 and Cct2 activity on FHV RNA replication in S2 cells, we generated alternative dsRNAs targeting different coding regions of these two genes and repeated RNAi-mediated knockdown experiments, including co-knockdown of both Cct1 and Cct2 mRNA (Fig. 5). We validated knockdown of Cct 1 and Cct 2 mRNA expression by RT-PCR, where we obtained an approximate $80-90 \%$ gene-specific reduction in steady state levels (Fig. 5A). Furthermore, quantitative analysis demonstrated a $30-35 \%$ reduction
A

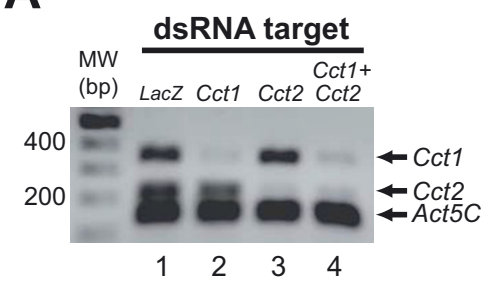

B

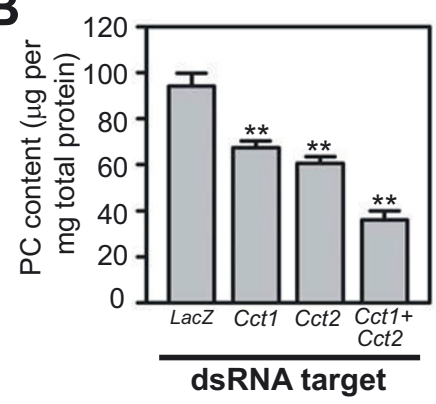

C

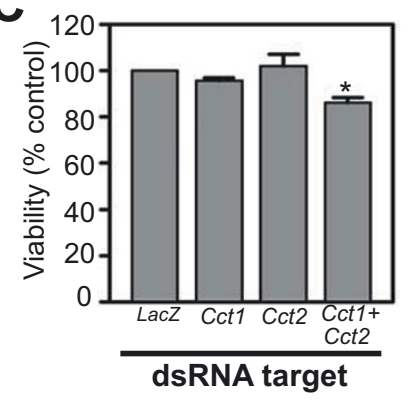

D

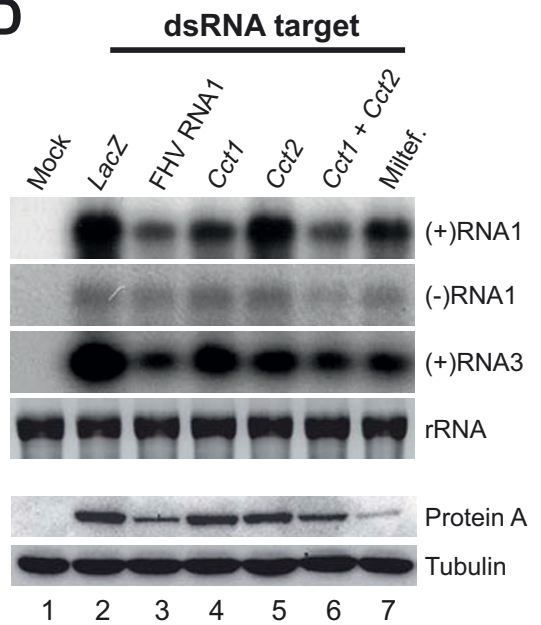

E

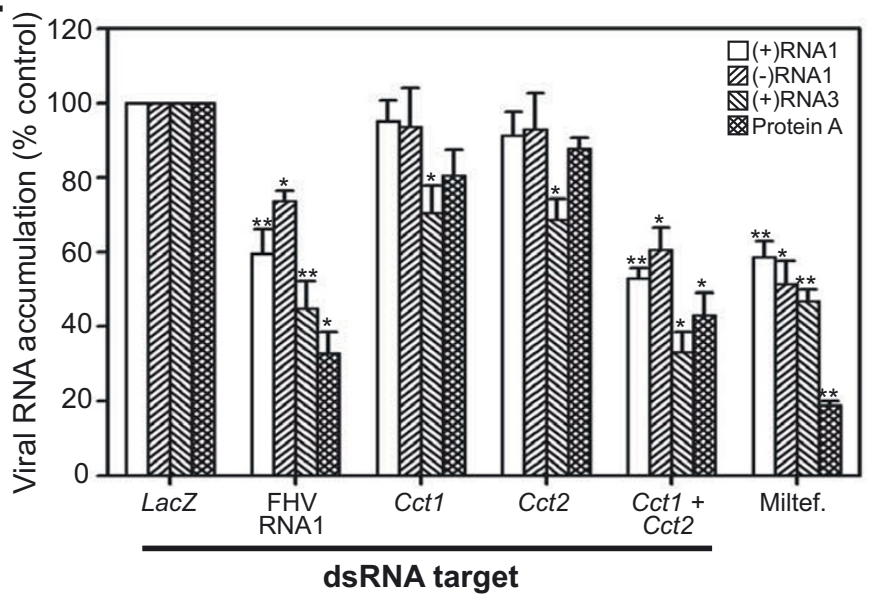

Figure 5 Verification of $C c t 1$ and $C c t 2$ roles in modulating FHV replication in infected S2 cells. (A) RT-PCR validation of Cct1 or Cct2 RNAimediated knockdown. Drosophila S2 cells were treated with dsRNAs specific for LacZ (lane 1), Cct1 (lane 2), Cct2 (lane 3), or both Cct1 and Cct2 (lane 4) for $72 \mathrm{~h}$, and gene-specific mRNA expression was examined by semi-quantitative RT-PCR as described in Fig. 2, except that only results from CDNA dilutions that produced submaximal signals are shown. (B) Total PC content in cells treated with the dsRNAs described above. PC levels were determined as in Fig. 3. (C) Viability of cells treated with dsRNAs described above determined by MTT assay. (D) FHV RNA accumulation in infected S2 cells after RNAi-mediated knockdown of Cct1, Cct2, or both. Mock-infected cells (lane 1), cells treated with the indicated dsRNA as described above or FHV RNA1 as a positive control (lanes 2-6), or treated with $50 \mu \mathrm{M}$ miltefosine (lane 7), were infected with FHV and viral-specific RNAs or protein were analyzed by northern blotting or immunoblotting $12 \mathrm{~h}$ after infection, respectively. For viral RNA analysis, blots for positive-sense $(+)$ and negative-sense (-) genomic RNA1 and subgenomic (+)RNA3 are shown. The decrease in (+)RNA1 accumulation in Cct1 knockdown cells (lane 4) was not consistently seen in all experiments. Ribosomal RNA (rRNA) bands detected by ethidium bromide staining are shown as loading controls. For protein analysis, blots for FHV protein A and the cellular loading control tubulin are shown. (E) Quantitative data for genomic (+)RNA1 and (-)RNA1, subgenomic (+)RNA3, and protein A accumulation in S2 cells treated with the indicated dsRNA or miltefosine after infection with FHV. Results are expressed as percentage of accumulation relative to LacZ dsRNA-treated control. Pvalue $<0.05^{*}$ or $0.005^{* *}$. 
in total PC levels with individual knockdown of either Cct 1 or Cct 2 mRNA, and a $\sim 60 \%$ reduction with knockdown of both genes (Fig. $5 \mathrm{~B}$ ). The incomplete knockdown of Cct1 and Cct 2 mRNA, the presence of a Cctindependent de novo PC synthesis pathway (see Fig. $4 \mathrm{~B}$ ), and the essential role that PC plays in cellular structure and metabolism all likely contributed to the lack of synergistic suppression of total PC levels with an RNAi-based approach that targeted one step in the biosynthetic pathway. We also examined cell viability by MTT assay, as disruption of CTP:phosphocholine cytidylyltransferase expression or function in mammalian cells results in enhanced susceptibility to apoptosis [36-38]. Individual knockdown of either Cct1 or Cct2 mRNA had no significant impact on cell viability, whereas co-knockdown of both genes resulted in a small but reproducible $15 \%$ reduction in cell viability as measured by MTT assay (Fig. 5C). We infected S2 cells with FHV after RNAi-mediated suppression of Cct1, Cct2, or both genes, and measured viral RNA and protein accumulation at $12 \mathrm{~h}$ after infection. Downregulation of either Cct1 or Cct2 individually suppressed FHV subgenomic (+)RNA3 accumulation by $\sim 30 \%$, but did not significantly reduce the accumulation of genomic
(+)RNA1, (-)RNA1, or protein A (Figs. 5D and 5E). However, downregulation of both Cct1 and Cct2 resulted in a 40-65\% reduction in the accumulation of all viral products examined, similar to the levels of suppression seen with the positive controls miltefosine and dsRNA directly targeting FHV RNA1. Although we cannot exclude the possibility that the small reduction in cell viability with co-knockdown of both Cct1 and Cct2 (Fig. 5C) adversely affected viral RNA or protein accumulation, potentially via apoptosis-mediated reduction in synthesis or stability, published studies have demonstrated that FHV replication is not sensitive to the antiviral effects of apoptosis induction in Drosophila cells [39]. These results indicated that genetic or pharmacologic disruption of PC synthesis inhibited FHV RNA replication in infected S2 cells.

To further examine the functional impact of Cct1 and Cct 2 on FHV RNA replication in the absence of infectious virus, we repeated experiments using RNAimediated downregulation of these genes in S2 cells expressing an RNA1 replicon (Fig. 6). We could not use stably transfected cells for genetic knockdown experiments, as the low level of FHV RNA replication in these cells in the absence of copper sulfate induction resulted
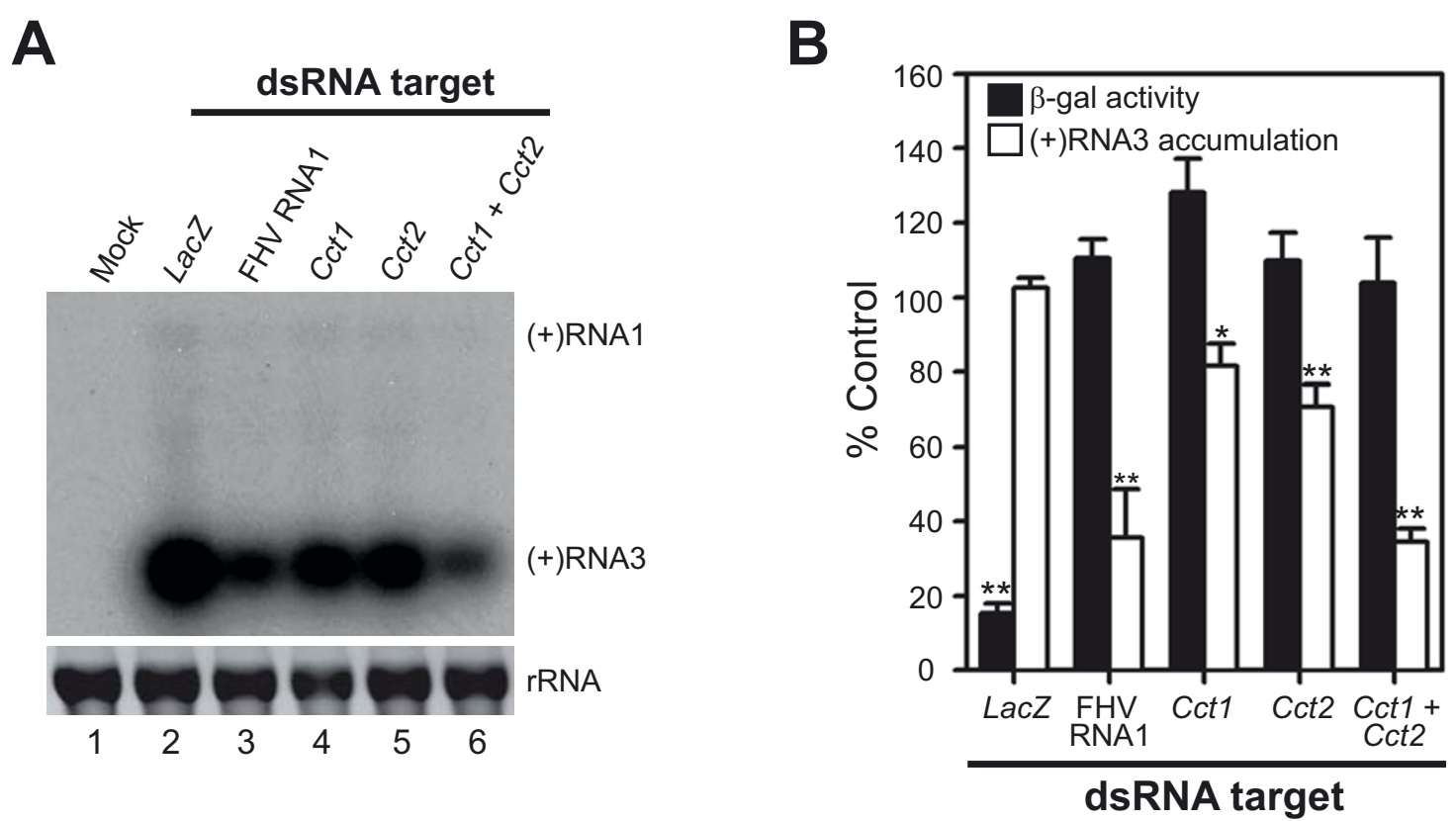

Figure 6 Verification of $C c t 1$ and Cct2 roles in modulating FHV RNA replication in replicon-bearing S2 cells. (A) Northern blot of FHV genomic (+)RNA1 and subgenomic (+)RNA3 accumulation in FHV replicon-bearing S2 cells after RNAi-mediated knockdown of Cct1, Cct2, or both. Mock transfected cells (lane 1) or cells treated with dsRNA against LacZ (lane 2), FHV RNA1 (lanes 3), Cct1 (lane 4), Cct2 (lane 5), or both Cct1 and Cct2 (lane 5) and co-transfected with pS2F1 and pS2LacZ were induced with $0.5 \mathrm{mM} \mathrm{Cu}^{2+}$ for $18 \mathrm{~h}$ and FHV RNA accumulation was determined by northern blotting as described in Fig. 5. The position of FHV subgenomic (+)RNA3 is shown on the right, and ribosomal RNA ( $r$ RNA) bands are shown as loading controls. The position of genomic (+)RNA1, which is barely detectable in transiently transfected S2 cells, is also shown on the right. (B) Quantitative data for subgenomic (+)RNA3 and $\beta$-galactosidase activity in S2 cells co-transfected with pS2F1 and pS2LacZ after RNAi-mediated knockdown of the indicated dsRNA targets. $P$-value $<0.05^{*}$ or $0.005^{* *}$. 
in protein B2 production that inhibited RNAi-mediated downregulation of cellular genes (data not shown). Therefore, we used a transient transfection approach. We treated S2 cells with dsRNAs for $48 \mathrm{~h}$, transfected cells with pS2F1 (see Fig. 1B) and control plasmid pS2LacZ, and measured FHV RNA replication by northern blotting and $\beta$-galactosidase activity by enzymatic assay $18 \mathrm{~h}$ after induction. We used pS2LacZ as a transfection control, as modulation of PC levels may influence transfection efficiency. Knockdown of either Cct1 or Cct2 suppressed FHV (+)RNA3 accumulation by 20$40 \%$ in pS2F1-transfected cells, whereas knockdown of both genes increased suppression to $65 \%$, similar to levels seen with control dsRNA targeted against FHV RNA1 (Figs. 6A and 6B). We did not quantitate genomic (+)RNA1 or protein A accumulation levels in transfected cells, as these viral products accumulated to low and almost undetectable levels in pS2F1-transfected cells (Fig. 6A and data not shown), such that attempts at quantitation would have been unreliable. Nevertheless, these results supported the conclusion that disruption of PC synthesis by genetic modulation of Cct1 or Cct2 inhibited FHV RNA replication.

Finally, we examined whether disruption of Cct1 or Cct2 expression directly suppressed FHV protein A accumulation or membrane association (Fig. 7), as we have previously demonstrated that cellular factors can impact viral RNA polymerase production [17,22] and hence facilitate an early step in RNA replication complex assembly (see Fig. 1C). Although protein A levels were decreased in FHV-infected cells with RNAimediated downregulation of both genes (Figs. 5D and $5 \mathrm{E}$ ), protein $\mathrm{A}$ accumulation in the setting of infectious virus or an FHV replicon is directly linked to RNA replication (see Fig. $1 \mathrm{C}$ ). Thus, we used a protein $\mathrm{A}$ expression vector, called pS2FA-HA (Fig. 7A), which is designed to optimize translation and prevent RNA replication via modification of 5' and 3' untranslated sequences that contain essential cis elements $[17,22]$. In contrast to the effects of Cct1- or Cct2-specific dsRNAs on FHV RNA replication (Figs. 5 and 6), knockdown of either gene had no effect on RNA polymerase accumulation in cells transfected with pS2FAHA (Fig. 7B), whereas dsRNAs against Hsp83 suppressed polymerase accumulation by $60 \%$, consistent with published studies demonstrating the important role of hsp90 chaperones in FHV protein A synthesis $[17,22]$. Furthermore, knockdown of Cct1, Cct2, or both genes did not alter the ability of protein $A$ to associate with intracellular membranes, as determined by differential centrifugation (Fig. 7C). These results indicated that PC synthesis was important for FHV RNA replication but not viral polymerase production or membrane association.
A

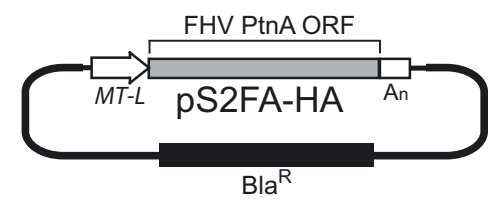

B
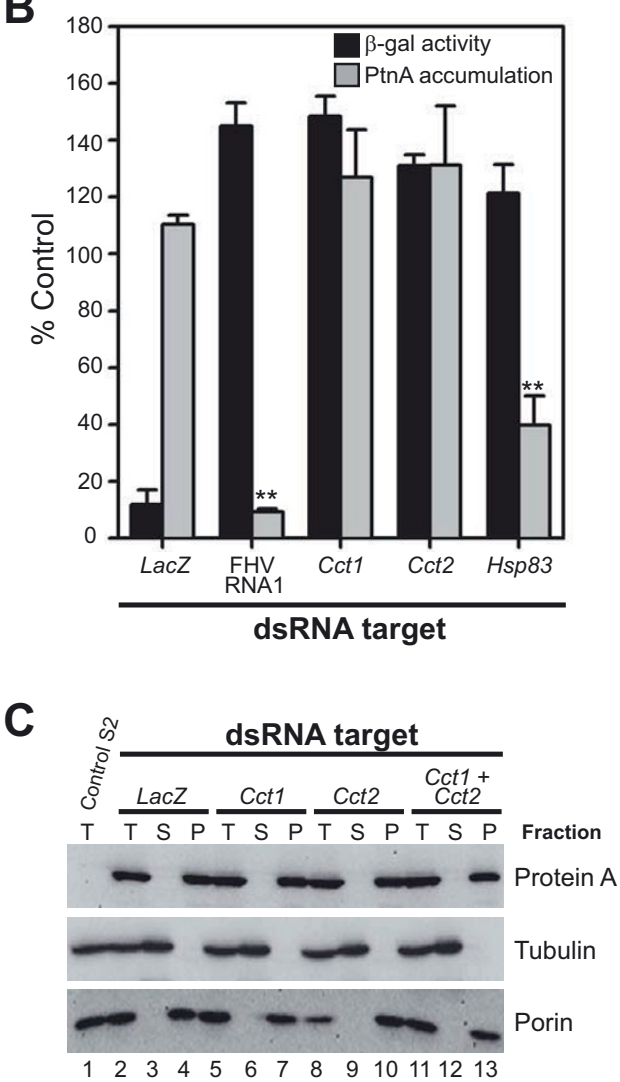

Figure 7 RNAi-mediated knockdown of Cct1 or Cct2 does not modulate FHV protein A accumulation or membrane association in S2 cells. (A) Schematic of FHV protein A expression vector with C-terminal HA tag. The RNA template produced from pS2FA-HA is optimized for translation by inclusion of a $5^{\prime}$ leader sequence $(L)$ and a $3^{\prime}$ polyadenylation signal $\left(A_{n}\right)$, but these alterations in addition to the C-terminal HA tag render the RNA template incompetent for viral RNA replication due to changes in essential $5^{\prime}$ and $3^{\prime}$ cis elements. (B) FHV protein A accumulation determined by quantitative immunoblotting and $\beta$-galactosidase activity determined by enzyme assay in $\mathbf{S} 2$ cells co-transfected with pS2FA-HA and pS2LacZ after RNAi-mediated knockdown of the indicated dsRNA targets. P-value $<0.05^{*}$ or $0.005^{* *}$. (C) S2 cells stably expressing either an empty vector (lane 1) or pS2FA-HA (lanes 2-13) were treated with dsRNA targeting LacZ (lanes 2-4), Cct1 (lanes 5-7), Cct2 (lanes 8-10), or both Cct1 and Cct2 (lanes 11-13) for $72 \mathrm{~h}$, induced with $0.5 \mathrm{mM} \mathrm{Cu}^{2+}$ for $18 \mathrm{~h}$, washed in PBS, and either lysed directly in SDS-PAGE buffer to obtain total fractions (T) or subjected to saponin-mediated permeabilization and differential centrifugation to obtain soluble $(\mathrm{S})$ and pellet $(\mathrm{P})$ fractions, which correspond to cytosolic and membrane protein fractions, respectively [22]. Fractions were analyzed by SDS-PAGE and immunoblotting for protein $A$, the cytosolic protein tubulin, or the membrane protein porin. 


\section{Discussion}

Global approaches such as transcriptomic, proteomic, and functional genomic analyses have provided important clues to critical host-pathogen interactions that influence virus replication and pathogenesis [40-47]. However, these approaches when used in isolation often provide an overwhelming amount of information that requires careful selection and validation. We have used an alternative approach that incorporates more targeted analyses including lipidomics to specifically examine the role of glycerophospholipid metabolism in FHV RNA replication. The results presented in this report further support the well described crucial role that intracellular membranes play in positive-strand RNA virus replication [3-5], but emphasize that cellular lipids are key membrane constituents for this particular host-pathogen interaction. Furthermore, this report provides new details on the impact of specific lipid metabolism pathways on viral RNA replication, and in particular PC biosynthesis. The identification of specific lipid metabolism pathways is an essential first step in the rationale design of antiviral strategies that target cellular rather than viral components. Indeed, the recognition that cholesterol metabolism is important for hepatitis $\mathrm{C}$ virus replication in cultured cells $[48,49]$ has led to direct clinical trials using cholesterol synthesis inhibitors [50].

The observation that PC is important for FHV RNA replication in cells is consistent with results published almost twenty years ago, which demonstrated that phospholipids enhance FHV RNA replication complex activity in isolated membrane fractions analyzed in vitro [21]. It also supports the hypothesis that one potential role cellular membranes play in viral RNA replication is to provide functional co-factors such as phospholipids for optimal RNA polymerase activity, and is consistent with published observations on the functional impact that phospholipids have on Semliki Forest virus nsP1 methyltransferase activity [51]. The precise mechanism(s) whereby phospholipids enhance FHV RNA replication complex activity is unknown, and there are multiple steps during process of viral RNA replication that could be influenced by these cellular components (see Fig. 1C). Interestingly, the observation that individual knockdown of Cct 1 or Cct 2 expression had an apparent preferential effect on subgenomic RNA3 production (Fig. 5) suggests that this particular step may be especially sensitive to cellular phospholipids. In addition to their potential roles as functional cofactors, membrane-resident lipids may also play other roles during RNA replication, such as providing a scaffold for replication complex targeting and assembly. Indeed, we recently demonstrated that FHV protein A is a lipid-binding protein with particular affinity for anionic phospholipids, including the mitochondrial-specific phospholipid cardiolipin [14]. Interestingly, we could not detect a significant physical interaction between $\mathrm{FHV}$ protein $\mathrm{A}$ and $\mathrm{PC}$ using in vitro assays [14], suggesting that PC may influence protein A activity indirectly or interact via some as yet unidentified intermediate protein or lipid.

Transcriptional array results suggested that FHV RNA replication stimulated $\mathrm{PC}$ synthesis in part via Cct1 or Cct2 upregulation, but the molecular mechanisms whereby FHV modulates lipid biosynthesis are unknown. One hypothesis is that FHV simply takes advantage of the cellular stress response to virus infection that may induce changes in phospholipid metabolism. However, published microarray results with cultured S2 cells infected with various pathogens, including viruses, bacteria, parasites, or fungi do not demonstrate a consistent upregulation of glycerophospholipid metabolism-related genes $[44,47,52]$. An alternative hypothesis is that FHV directly and specifically modulates glycerophospholipid metabolism. Interestingly, the enzyme encoded by Drosophila Cct1 is activated by cellular lipids, and in particular cardiolipin [24], suggesting a potential link with the observed protein A-cardiolipin interaction [14]. Phosphatidic acid, which represents the essential precursor in the synthesis of all glycerophospholipids [35] (see also Fig. 4B), also physically interacts with FHV protein A [14] and could serve as a potential conduit for regulation. Although these hypotheses are speculative and cannot directly explain transcriptional upregulation, they are readily testable with FHV using established in vitro and in vivo systems.

We focused on PC for this report, but our results do not exclude the potential important role of other cellular phospholipids in FHV RNA replication. Indeed, both transcriptomic (Fig. 2A) and functional genetic (Fig. 4A) analyses identified numerous additional candidate lipid metabolism-associated genes linked to FHV RNA replication. Furthermore, the lipidomics analysis examined total cellular membrane lipid content, whereas FHV RNA replication complexes localize to outer mitochondrial membranes and induce dramatic morphological and structural changes $[11,15]$. Although most glycerophospholipids, and in particular the highly abundant PC and $\mathrm{PE}$, are widely distributed in membranes throughout the cell $[29,53]$, detailed analyses of mitochondrial outer membrane lipids may reveal interesting and potentially more dramatic changes than we observed with the total cellular lipid analyses. Experiments are currently in progress to isolate and examine mitochondrial and submitochondrial fractions from cells with active FHV RNA replication complexes using well established techniques [54]. In addition, the observation that specific acyl chain 
modifications that result in longer unsaturated PC species were seen in FHV-infected cells suggests that particular lipid changes apart from the phospholipid head group also may play important roles in viral RNA replication. This is consistent with the demonstration that brome mosaic virus RNA replication is suppressed in yeast with a deletion of the enzyme $\Delta 9$ fatty acid desaturase [55]. FHV replicates robustly in Saccharomyces cerevisiae [12,56,57], and preliminary results suggest that FHV RNA replication in yeast is also influenced by alterations in PC metabolism (K. Stapleford and D. Miller, unpublished results). Phospholipid metabolism pathways and their regulation have been well studied in yeast [58], and therefore this genetically tractable host provides an excellent companion for parallel studies with Drosophila cells to further examine the impact of lipid metabolism on FHV RNA replication.

\section{Conclusions}

In this study we demonstrate through a combination of complementary targeted and global analyses that glycerophospholipids, and in particular PC, play an important role in FHV RNA replication. These results enhance our understanding of the essential function that cellular membranes have in facilitating positive-strand RNA virus replication, and suggest that modulating cellular phospholipid synthesis may represent a novel approach for targeted antiviral development.

\section{Methods}

\section{Cells and virus}

Drosophila S2 cells were cultured in Schneider's Drosophila media (SDM) and transfected with inducible expression plasmids as previously described [17]. Sucrose gradient-purified FHV [11] was used for all infection experiments.

\section{Plasmids, antibodies, and chemicals}

Standard molecular biology procedures were used for all cloning steps. The FHV RNA1 replicon expression plasmid pS2F1 (Fig. 1B), the protein A expression plasmid pS2FA-HA, and the control plasmid pS2LacZ have been previously described [17]. The control plasmid $\mathrm{pS} 2 \mathrm{~F} 1_{\mathrm{fs}}$, which contains an early frameshifting mutation in the protein A coding region (Fig. 1B) and hence will not produce a functional cis replicon transcript $[6,12]$, was generated by cloning the ScaI/BsrGI fragment from $\mathrm{pF}_{\mathrm{fs}}$ [6] into the MscI/Acc65I sites of pMT-V5/HisA (Invitrogen, Carlsbad, CA). Rabbit polyclonal antibodies against FHV protein A have been previously described [11], and antibodies against FHV protein B2 were generously provided by Paul Ahlquist (University of Wisconsin-Madison). Rabbit polyclonal antibodies against the hemagglutinin (HA) epitope tag or the voltage- dependent anion channel porin were purchased from Santa Cruz Biotechnology (Santa Cruz, CA) or Affinity Bioreagents (Golden, $\mathrm{CO}$ ), respectively, while monoclonal antibodies against tubulin were purchased from the Developmental Studies Hybridoma Bank (University of Iowa, Iowa City, IA). All secondary reagents for ELISA and immunoblot analyses were purchased from Jackson Immunoresearch (West Grove, PA). The CTP:phosphocholine cytidyltransferase inhibitor miltefosine (1-hexadecylphosphorylcholine) was purchased from Calbiochem (San Diego, CA) and stored as a $100 \mathrm{mM}$ stock solution in dimethylsulfoxide at $-20^{\circ} \mathrm{C}$. Oleic acid (cis-9-octadecenoic acid) was purchased from Sigma (St. Louis, MO) and stored as an undiluted stock solution at $-20^{\circ} \mathrm{C}$.

FHV infection, replicon induction, and total RNA isolation Cells were either infected with FHV at a multiplicity of infection of 10 as previously described [11] and harvested at 12 to $24 \mathrm{~h}$ after infection, or transiently transfected with pS2F1 and pS2LacZ as previously described [17] and harvested at $18 \mathrm{~h}$ after induction with $0.5 \mathrm{mM}$ copper sulfate. For microarray and phospholipid analyses, S2 cells stably transfected with pS2F1 or pS2F1 $1_{\mathrm{fs}}$ were induced with $1 \mathrm{mM}$ copper sulfate and harvested at $18 \mathrm{~h}$ after induction. Total RNA was isolated using TRIzol reagent (Invitrogen) per the manufacturer's instruction. For microarray and RT-PCR analyses, RNA was further processed by digestion with RQ1 DNAse and subsequent purification with RNAsy columns (Qiagen, Valencia, CA). Total RNA purity, integrity, and concentration were checked by spectrophotometry and agarose gel electrophoresis, and samples were stored at $-80^{\circ} \mathrm{C}$ until analysis.

\section{Affymetrix microarray data acquisition and analysis}

Affymetrix Drosophila Genome 1.0 or 2.0 microarrays were used for FHV infection or replicon experiments, respectively, and biotinylated amplified cRNAs were produced using Affymetrix GeneChip target labelling kits per the manufacturer's instructions. Microarrays were scanned with an Affymetrix Scanner 3000, and complete original data files for all microarray experiments have been deposited in the Gene Expression Omnibus (GEO) database http://www.ncbi.nlm.nih.gov/ geo/ under the accession number GSE15469.

Genomatix ChipInspector software package was used for primary microarray data analyses. This program uses a single probe method with an enhanced statistics package based on a SAM algorithm [59] that incorporates a $t$-test with a permuted artificial background to reduce false-positives. The following parameters were chosen to identify sets of up- or downregulated transcripts: (i) false-discovery rate of $1 \%$; (ii) three probe 
minimum coverage; and (iii) 1.5 -fold change from control. Similar results were obtained when microarray data were analyzed with the Affymetrix package of Bioconductor [60]. The FlyBase database (FB2008_09; http:// flybase.org/) was used to identify Gene Ontology (GO) terms, genetic interaction partners, and yeast-human orthologs for Drosophila genes identified in the microarray analyses.

\section{Semiquantitative RT-PCR validation}

First-strand cDNA synthesis was completed with equal amount of total RNA using oligo-dT primers and the Superscript II First Strand synthesis kit (Invitrogen) per the manufacturer's instructions. Ten-fold dilutions of cDNA were used for PCR reactions with gene-specific primer sets (Table 2) under the following conditions: $200 \mathrm{nM}$ primers, $58^{\circ} \mathrm{C}$ annealing temperature, and 30 cycles. RT-PCR products were analyzed by agarose gel electrophoresis and ethidium bromide staining.

\section{Phospholipid analysis}

Total PC content was determined using a modified phospholipase D-based enzymatic method initially developed for measurement of plasma PC levels [27]. Briefly, S2 cells were pelleted at $1,000 \times \mathrm{g}$ for $5 \mathrm{~min}$ at $4^{\circ} \mathrm{C}$, washed twice with Tris-buffered saline (TBS) $(100 \mathrm{mM}$ sodium chloride, $50 \mathrm{mM}$ Tris, $\mathrm{pH} 7.2$ ), lysed with $1 \%$ Triton X-100, and incubated with reaction buffer containing $50 \mathrm{mM}$ Tris ( $\mathrm{pH} 7.2), 0.64 \mathrm{M}$ calcium chloride, $0.73 \mathrm{M} \quad \mathrm{N}$-ethyl- $N$-(2-hydroxy-3-sulfopropyl)-3,5dimethoxyanaline, $0.73 \mathrm{M} 4$-aminoantipyrine, $120 \mathrm{U} / \mathrm{ml}$ PC-specific phospholipase D, $0.5 \mathrm{U} / \mathrm{ml}$ choline oxidase, and $20 \mathrm{U} / \mathrm{ml}$ peroxidase. Reactions were incubated at $37^{\circ} \mathrm{C}$ for $2 \mathrm{~h}$ and the absorbance at $595 \mathrm{~nm}$ was measured using a FLUOstar Omega microplate reader (BMG Labtech, Durham, NC). Quantitative PC

Table 2 Oligonucleotide sequences.

\begin{tabular}{cc}
\hline $\begin{array}{c}\text { Name/ } \\
\text { description }\end{array}$ & Sequence $\left(\mathbf{5}^{\prime} \boldsymbol{\rightarrow} \mathbf{3}^{\prime}\right)$ \\
\hline Cct1-for & ${ }^{*}$ GAGATGGCCGAGAAGTTGAG \\
\hline Cct1-rev & ${ }^{*}$ GGATTCCCTCGATTCTCACA \\
\hline Cct2-for & ${ }^{*}$ ACTTGGGCCTGAGACTGCTA \\
\hline Cct2-rev & ${ }^{*}$ CTTCGGCATTCTGTCCATT \\
\hline Act5C-for & ATGTGTGACGAAGAAGTTGT \\
\hline Act5C-rev & GTCCCAGTTGGTCACGATACC \\
\hline FHV1-RNAi-for & TAATACGACTCACTATAGGGATGACTCTAAAAGTATTC \\
\hline FHV1-RNAi-rev & TAATACGACTCACTATAGGGTCTGCTAGCGATAAAC \\
\hline S2-RNAi-T7 & TAATACGACTCACTATAGGGAGACCACGGGCGGGT \\
\hline
\end{tabular}

The T7 RNA polymerase promoter is in bold italics type for FHV1 RNAi-for, FHV1 RNAi-rev, and S2-RNAi-T7 oligonucleotides, and was also added to the 5' end of the Cct1 and Cct2 oligonucleotides (asterisks) that were used to generate dsRNAs. concentrations were calculated using a standard curve generated with purified PC. Parallel total protein concentrations were determined with cell lysates prepared using TBS and $1 \% n$-octyl- $\beta$-D-glucopuranoside and BioRad total protein reagent with bovine serum albumin as the standard. For analysis of individual cellular phospholipids, S2 cells were pelleted, washed twice with TBS, and lipids were extracted with chloroform:methanol using the method of Bligh and Dyer [61]. Final extract samples were dried under vacuum and analyzed for polar lipid content by ESI-MS/MS at the Kansas Lipidomics Research Center http://www.k-state.edu/ lipid/lipidomics/index.htm.

\section{dsRNA production and RNAi induction}

The O'Farrell RNAi library was purchased from the Drosophila Genome Research Center (DGRC). This collection contains 300-600 bp double-stranded cDNAs corresponding to greater than 7,000 individual phylogenetically conserved Drosophila genes [30], which can all be amplified by PCR using a common oligonucleotide primer (S2-RNAi-T7) that contains a GC-rich linker and T7 RNA polymerase promoter (Table 2). PCR products were generated using Eppendorf Mastermix with $200 \mathrm{nM}$ primers, annealing temperature of $62^{\circ} \mathrm{C}$, and 40 cycles. If no product was obtained after the first amplification, a second PCR was done using an aliquot of the first reaction as a template. PCR products were analyzed by non-denaturing gel electrophoresis and ethidium bromide staining and purified using a PCR cleanup kit (Promega) per the manufacturer's instruction. To generate the cDNA templates for $C c t 1$ and $C c t 2$ validation studies, candidate RNAi targets that differed from the O'Farrell library constructs were identified using the ERNAi program [62]. To generate control FHV RNA1specific dsRNA we targeted nucleotides 40-735, which include the initiator AUG codon. RT-PCR with genespecific primer sets that incorporated a T7 RNA polymerase promoter (Table 2) were used to generate PCR templates for dsRNA generation. Control $L a c Z$ and Hsp83 cDNAs were produced as previously described [17].

RNAs were generated using a T7 Megascript kit (Ambion) per the manufacturer's instruction, purified by phenol-chloroform extraction and isopropanol precipitation, and resuspended in RNAse-free water. dsRNAs were generated by heating samples to $65^{\circ} \mathrm{C}$ for $30 \mathrm{~min}$ and cooling slowly to room temperature. Samples were analyzed by non-denaturing agarose gel electrophoresis and ethidium bromide staining to ensure the formation of properly sized dsRNA products, quantitated by spectrophotometry, and stored at $-20^{\circ} \mathrm{C}$ until used for RNAi studies. RNAi was induced in cultured S2 cells as previously described [17]. Briefly, $10 \mu \mathrm{g}$ 
dsRNA was added to $10^{6}$ cells in $0.5 \mathrm{ml}$ serum-free $\mathrm{SDM}$, incubated at $25^{\circ} \mathrm{C}$ for $1 \mathrm{~h}, 0.5 \mathrm{ml} \mathrm{SDM}$ with $20 \%$ fetal bovine serum was added and cells were incubated for an additional 48-72 $\mathrm{h}$ prior to FHV infection or replicon transfection.

\section{FHV RNA replication analyses}

To facilitate the analysis of FHV RNA replication in a medium throughput format, an FHV protein B2 capture ELISA was developed. FHV protein B2-specific polyclonal antibodies for detection were purified from rabbit antisera by Staphylococcus aureus protein A affinity chromatography and biotinylated with 6-(biotinamidocaproylamido)caproic acid $N$-hydroxysuccinimide ester (Sigma) per the manufacturer's instructions. For capture antibodies, total immunoglobulins from FHV protein B2 antisera were isolated by saturated ammonium sulfate precipitation. Flexible microassay plates were coated with $5 \mu \mathrm{g} / \mathrm{ml}$ capture antibody in phosphate-buffered saline (PBS) (100 mM sodium chloride, $50 \mathrm{mM}$ sodium phosphate, $\mathrm{pH} 7.4$ ) overnight at $4^{\circ} \mathrm{C}$, blocked with $1 \%$ non-fat milk, and S2 cell lysates in PBS with $0.5 \%$ Triton X-100 were incubated in duplicate wells for $2 \mathrm{~h}$ at room temperature. Plates were washed extensively with TBS and $0.1 \%$ Tween 20 , incubated with $1.25 \mu \mathrm{g} / \mathrm{ml}$ biotinylated detection antibody followed by streptavidin-alkaline phosphatase. Plates were developed with $1 \mathrm{mg} / \mathrm{ml} p$-nitrophenyl phosphate in $50 \mathrm{mM}$ sodium carbonate buffer $(\mathrm{pH}$ 10.0) with $1 \mathrm{mM}$ magnesium chloride and the absorbance at $405 \mathrm{~nm}$ was measured with the microplate reader described above. Initial optimization experiments demonstrated a high sensitivity for this assay, where lysates from less than ten S2 cells expressing a pS2F1-based replicon produced a positive signal (data not shown). Northern blot analyses for FHV-specific RNAs, immunoblot analyses for protein A accumulation, saponin-mediated permeabilization and differential centrifugation, and $\beta$-galactosidase assays were done as previously described $[17,22]$.

\section{Viability assays}

Viability assays were performed using 3- [4,5dimethylthizol-2-yl]-2,5-diphenyltetrazolium bromide (MTT) as previously described [63].

\section{Statistical analyses}

Microarray statistical analyses are described above. For additional statistical analyses a two-tailed $t$ test assuming equal variances was used and a $p$ value of $<0.05$ was considered significant. All results are representative or a composite of at least three independent experiments, where quantitative data represent the mean \pm standard errors of the mean.

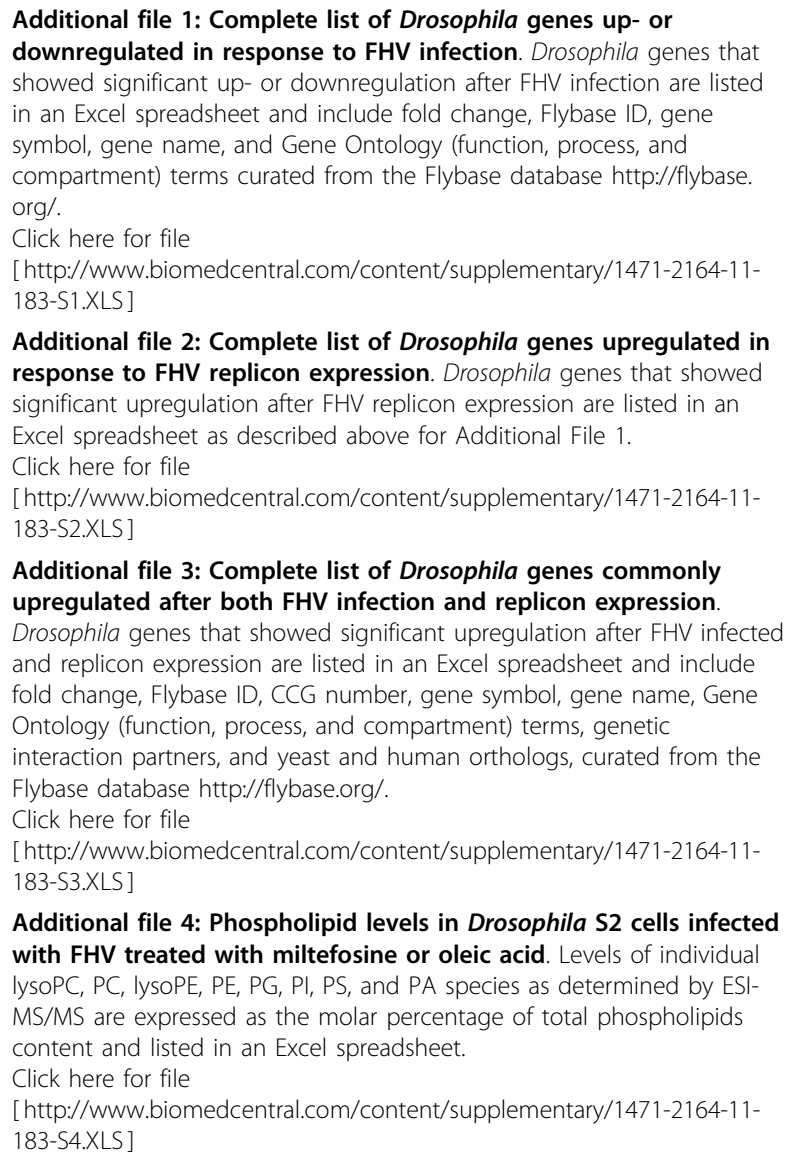

[http://www.biomedcentral.com/content/supplementary/1471-2164-11183-S2.XLS]

Additional file 3: Complete list of Drosophila genes commonly upregulated after both FHV infection and replicon expression Drosophila genes that showed significant upregulation after FHV infected and replicon expression are listed in an Excel spreadsheet and include fold change, Flybase ID, CCG number, gene symbol, gene name, Gene Ontology (function, process, and compartment) terms, genetic

interaction partners, and yeast and human orthologs, curated from the Flybase database http://flybase.org/.

Click here for file

[http://www.biomedcentral.com/content/supplementary/1471-2164-11183-S3.XLS ]

Additional file 4: Phospholipid levels in Drosophila S2 cells infected with FHV treated with miltefosine or oleic acid. Levels of individual IysOPC, PC, lysoPE, PE, PG, PI, PS, and PA species as determined by ESIMS/MS are expressed as the molar percentage of total phospholipids content and listed in an Excel spreadsheet.

Click here for file

[http://www.biomedcentral.com/content/supplementary/1471-2164-11183-S4.XLS]

\section{Acknowledgements}

We thank Donna Gschwend and Allison Simms for assistance and all laboratory members for their helpful comments on the research and manuscript. We thank Paul Ahlquist for provided reagents and James McDonald and the University of Michigan Affymetrix Microarray Core for assistance with microarray data acquisition and analyses. We also thank Mary Roth, Ruth Welti, and the Kansas Lipidomics Research Center Analytical Laboratory for ESI-MS/MS phospholipid analyses. This work was supported by National Institutes of Health grants K08-Al01770, R01-Al062749, and T32GM007315.

\section{Author details}

'Departments of Internal Medicine, University of Michigan Medical School, Ann Arbor, MI 48109, USA. ${ }^{2}$ Microbiology \& Immunology, University of Michigan Medical School, Ann Arbor, Ml 48109, USA. ${ }^{3}$ Program in Cellular and Molecular Biology, University of Michigan Medical School, Ann Arbor, MI 48109, USA. ${ }^{4}$ Section of Microbial Pathogenesis, Yale University School of Medicine, New Haven, CT 06536, USA.

\section{Authors' contributions}

KMC, KAS, and DJM conducted all the experiments. DJM wrote the manuscript and coordinated the research efforts. All authors read and approved the final manuscript.

Received: 30 July 2009 Accepted: 17 March 2010 Published: 17 March 2010

\section{References}

1. Fox JL: Antivirals become a broader enterprise. Nat Biotechnol 2007, 25(12):1395-1402. 
2. Miller S, Krijnse-Locker J: Modification of intracellular membrane structures for virus replication. Nat Rev Microbiol 2008, 6(5):363-374.

3. Ahlquist $P$, Noueiry $A O$, Lee WM, Kushner DB, Dye BT: Host factors in positive-strand RNA virus genome replication. J Virol 2003, 77(15):8181-8186.

4. Denison MR: Seeking membranes: positive-strand RNA virus replication complexes. PLoS Biol 2008, 6(10):e270.

5. Salonen A, Ahola T, Kaariainen L: Viral RNA replication in association with cellular membranes. Curr Top Microbiol Immunol 2005, 285:139-173.

6. Price BD, Roeder M, Ahlquist P: DNA-Directed expression of functional flock house virus RNA1 derivatives in Saccharomyces cerevisiae, heterologous gene expression, and selective effects on subgenomic mRNA synthesis. J Virol 2000, 74(24):11724-11733.

7. Miller DJ, Schwartz MD, Dye BT, Ahlquist P: Engineered retargeting of viral RNA replication complexes to an alternative intracellular membrane. $J$ Virol 2003, 77(22):12193-12202.

8. Selling BH, Allison RF, Kaesberg P: Genomic RNA of an insect virus directs synthesis of infectious virions in plants. Proc Natl Acad Sci USA 1990 87(1):434-438.

9. Ball LA: Requirements for the self-directed replication of Flock House virus RNA 1. J Virol 1995, 69(2):720-727.

10. Lu R, Maduro M, Li F, Li HW, Broitman-Maduro G, Li WX, Ding SW: Animal virus replication and RNAi-mediated antiviral silencing in Caenorhabditis elegans. Nature 2005, 436(7053):1040-1043.

11. Miller DJ, Schwartz MD, Ahlquist P: Flock House virus RNA replicates on outer mitochondrial membranes in Drosophila cells. J Virol 2001, 75(23):11664-11676.

12. Miller DJ, Ahlquist P: Flock House virus RNA polymerase is a transmembrane protein with amino-terminal sequences sufficient for mitochondrial localization and membrane insertion. J Virol 2002, 76(19):9856-9867.

13. Li H, Li WX, Ding SW: Induction and suppression of RNA silencing by an animal virus. Science 2002, 296(5571):1319-1321.

14. Stapleford KA, Rapaport D, Miller DJ: Mitochondrion-enriched anionic phospholipids facilitate Flock House virus RNA polymerase membrane association. J Virol 2009, 83(9):4498-4507.

15. Kopek BG, Perkins G, Miller DJ, Ellisman MH, Ahlquist P: Three-dimensional analysis of a viral RNA replication complex reveals a virus-induced miniorganelle. PLOS Biol 2007, 5(9):e220

16. Lanman J, Crum J, Deerinck TJ, Gaietta GM, Schneemann A, Sosinsky GE, Ellisman $\mathrm{MH}$, Johnson JE: Visualizing Flock House virus infection in Drosophila cells with correlated fluorescence and electron microscopy. J Struct Biol 2008, 161(3):439-446.

17. Kampmueller KM, Miller DJ: The cellular chaperone heat shock protein 90 facilitates Flock House virus RNA replication in Drosophila cells. J Virol 2005, 79(11):6827-6837

18. Guinea R, Carrasco L: Phospholipid biosynthesis and poliovirus genome replication, two coupled phenomena. EMBO J 1990, 9:2011-2016.

19. Perez L, Guinea R, Carrasco L: Synthesis of Semliki Forest virus RNA requires continuous lipid synthesis. Virology 1991, 183(1):74-82.

20. WU SX, Kaesberg P: Synthesis of template-sense, single-strand Flock House virus RNA in a cell-free replication system. Virology 1991, 183(1):392-396.

21. Wu SX, Ahlquist P, Kaesberg P: Active complete in vitro replication of nodavirus RNA requires glycerophospholipid. Proc Natl Acad Sci USA 1992, 89(23):11136-11140.

22. Castorena KM, Weeks SA, Stapleford KA, Cadwallader AM, Miller DJ: A functional heat shock protein 90 chaperone is essential for efficient Flock House virus RNA polymerase synthesis in Drosophila cells. J Virol 2007, 81(16):8412-8420

23. Gupta T, Schupbach T: Cct1, a phosphatidylcholine biosynthesis enzyme, is required for Drosophila oogenesis and ovarian morphogenesis. Development 2003, 130(24):6075-6087.

24. Helmink BA, Friesen JA: Characterization of a lipid activated CTP: phosphocholine cytidylyltransferase from Drosophila melanogaster. Biochim Biophys Acta 2004, 1683(1-3):78-88.

25. Tilley DM, Evans CR, Larson TM, Edwards KA, Friesen JA: Identification and characterization of the nuclear isoform of Drosophila melanogaster CTP: phosphocholine cytidylyltransferase. Biochemistry 2008, 47(45):11838-11846.
26. Guo Y, Walther TC, Rao M, Stuurman N, Goshima G, Terayama K, Wong JS, Vale RD, Walter $P$, Farese RV: Functional genomic screen reveals genes involved in lipid-droplet formation and utilization. Nature 2008 453(7195):657-661.

27. Hojjati MR, Jiang XC: Rapid, specific, and sensitive measurements of plasma sphingomyelin and phosphatidylcholine. J Lipid Res 2006, 47(3):673-676.

28. Boggs K, Rock CO, Jackowski S: The antiproliferative effect of hexadecylphosphocholine toward HL60 cells is prevented by exogenous lysophosphatidylcholine. Biochim Biophys Acta 1998, 1389(1):1-12.

29. Jones HE, Harwood JL, Bowen ID, Griffiths G: Lipid composition of subcellular membranes from larvae and prepupae of Drosophila melanogaster. Lipids 1992, 27(12):984-987.

30. Foley $\mathrm{E}, \mathrm{O}^{\prime}$ Farrell $\mathrm{PH}$ : Functional dissection of an innate immune response by a genome-wide RNAi screen. PLOS Biol 2004, 2(8):E203.

31. Chao JA, Lee JH, Chapados BR, Debler EW, Schneemann A, Williamson JR Dual modes of RNA-silencing suppression by Flock House virus protein B2. Nat Struct Mol Biol 2005, 12(11):952-957.

32. Fournier D, Bride JM, Karch F, Berge JB: Acetylcholinesterase from Drosophila melanogaster. Identification of two subunits encoded by the same gene. FEBS Lett 1988, 238(2):333-337.

33. Giot L, Bader JS, Brouwer C, Chaudhuri A, Kuang B, Li Y, Hao YL, Ooi CE,

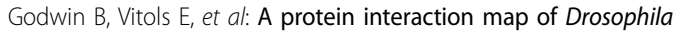
melanogaster. Science 2003, 302(5651):1727-1736.

34. Williams BC, Garrett-Engele CM, Li Z, Williams EV, Rosenman ED, Goldberg ML: Two putative acetyltransferases, san and deco, are required for establishing sister chromatid cohesion in Drosophila. Curr Biol 2003, 13(23):2025-2036

35. Kent C: Eukaryotic phospholipid biosynthesis. Annu Rev Biochem 1995, 64:315-343

36. Ramos B, El Mouedden M, Claro E, Jackowski S: Inhibition of CTP: phosphocholine cytidylyltransferase by C(2)-ceramide and its relationship to apoptosis. Mol Pharmacol 2002, 62(5):1068-1075.

37. Cui Z, Houweling M, Chen MH, Record M, Chap H, Vance DE, Terce F: A genetic defect in phosphatidylcholine biosynthesis triggers apoptosis in Chinese hamster ovary cells. J Biol Chem 1996, 271(25):14668-14671.

38. Miquel K, Pradines A, Terce F, Selmi S, Favre G: Competitive inhibition of choline phosphotransferase by geranylgeraniol and farnesol inhibits phosphatidylcholine synthesis and induces apoptosis in human lung adenocarcinoma A549 cells. J Biol Chem 1998, 273(40):26179-26186.

39. Settles EW, Friesen PD: Flock House virus induces apoptosis by depletion of Drosophila inhibitor-of-apoptosis protein DIAP1. J Virol 2008, 82(3):1378-1388

40. Kushner DB, Lindenbach BD, Grdzelishvili VZ, Noueiry AO, Paul SM, Ahlquist P: Systematic, genome-wide identification of host genes affecting replication of a positive-strand RNA virus. Proc Natl Acad Sci USA 2003, 100(26):15764-15769.

41. Panavas T, Serviene E, Brasher J, Nagy PD: Yeast genome-wide screen reveals dissimilar sets of host genes affecting replication of RNA viruses. Proc Natl Acad Sci USA 2005, 102(20):7326-7331.

42. Cherry S, Doukas T, Armknecht S, Whelan S, Wang H, Sarnow P, Perrimon N: Genome-wide RNAi screen reveals a specific sensitivity of IREScontaining RNA viruses to host translation inhibition. Genes Dev 2005, 19(4):445-452.

43. Cherry S, Silverman N: Host-pathogen interactions in Drosophila : new tricks from an old friend. Nat Immunol 2006, 7(9):911-917.

44. Irving P, Troxler L, Heuer TS, Belvin M, Kopczynski C, Reichhart JM, Hoffmann JA, Hetru C: A genome-wide analysis of immune responses in Drosophila. Proc Natl Acad Sci USA 2001, 98(26):15119-15124.

45. Hao L, Sakurai A, Watanabe T, Sorensen E, Nidom CA, Newton MA, Ahlquist $\mathrm{P}$, Kawaoka Y: Drosophila RNAi screen identifies host genes important for influenza virus replication. Nature 2008, 454(7206):890-893.

46. Go EP, Wikoff WR, Shen Z, O'Maille G, Morita H, Conrads TP, Nordstrom A, Trauger SA, Uritboonthai W, Lucas DA, et al: Mass spectrometry reveals specific and global molecular transformations during viral infection. $J$ Proteome Res 2006, 5(9):2405-2416.

47. Dostert C, Jouanguy E, Irving P, Troxler L, Galiana-Arnoux D, Hetru C, Hoffmann JA, Imler JL: The Jak-STAT signaling pathway is required but not sufficient for the antiviral response of Drosophila. Nat Immunol 2005, 6(9):946-953. 
48. Ye J: Reliance of host cholesterol metabolic pathways for the life cycle of hepatitis C virus. PLoS Pathog 2007, 3(8):e108.

49. Amemiya F, Maekawa S, Itakura Y, Kanayama A, Matsui A, Takano S, Yamaguchi T, Itakura J, Kitamura T, Inoue T, et al: Targeting lipid metabolism in the treatment of hepatitis $C$ virus infection. $J$ Infect Dis 2008, 197(3):361-370.

50. Bader T, Fazili J, Madhoun M, Aston C, Hughes D, Rizvi S, Seres K, Hasan M: Fluvastatin inhibits hepatitis C replication in humans. Am J Gastroenterol 2008, 103(6):1383-1389.

51. Ahola T, Lampio A, Auvinen P, Kaariainen L: Semliki Forest virus mRNA capping enzyme requires association with anionic membrane phospholipids for activity. EMBO J 1999, 18(11):3164-3172.

52. Roxstrom-Lindquist $\mathrm{K}$, Terenius $\mathrm{O}$, Faye I: Parasite-specific immune response in adult Drosophila melanogaster : a genomic study. EMBO Rep 2004, 5(2):207-212.

53. van Meer G, Voelker DR, Feigenson GW: Membrane lipids: where they are and how they behave. Nat Rev Mol Cell Biol 2008, 9(2):112-124.

54. Greenawalt JW: Survey and update of outer and inner mitochondrial membrane separation. Methods Enzymol 1979, 55:88-98.

55. Lee WM, Ishikawa M, Ahlquist P: Mutation of host $\Delta 9$ fatty acid desaturase inhibits brome mosaic virus RNA replication between template recognition and RNA synthesis. J Virol 2001, 75(5):2097-2106.

56. Price $B D$, Ahlquist $P$, Ball $L A$ : DNA-directed expression of an animal virus RNA for replication- dependent colony formation in Saccharomyces cerevisiae. J Virol 2002, 76(4):1610-1616.

57. Price $B D$, Rueckert RR, Ahlquist $P$ : Complete replication of an animal virus and maintenance of expression vectors derived from it in Saccharomyces cerevisiae. Proc Natl Acad Sci USA 1996, 93(18):9465-9470.

58. Kohlwein SD, Daum G, Schneiter R, Paltauf F: Phospholipids: synthesis, sorting, subcellular traffic - the yeast approach. Trends Cell Biol 1996, 6(7):260-266.

59. Tusher VG, Tibshirani R, Chu G: Significance analysis of microarrays applied to the ionizing radiation response. Proc Natl Acad Sci USA 2001, 98(9):5116-5121.

60. Irizarry RA, Hobbs B, Collin F, Beazer-Barclay YD, Antonellis K, Scherf U, Speed TP: Exploration, normalization, and summaries of high density oligonucleotide array probe level data. Biostatistics 2003, 4(2):249-264.

61. Bligh EG, Dyer WJ: A rapid method of total lipid extraction and purification. Can J Biochem Physiol 1959, 37(8):911-917.

62. Arziman Z, Horn T, Boutros M: E-RNAi: a web application to design optimized RNAi constructs. Nucleic Acids Res 2005, 33 Web Server: W582-588.

63. Castorena KM, Peltier DC, Peng W, Miller DJ: Maturation-dependent responses of human neuronal cells to western equine encephalitis virus infection and type I interferons. Virology 2008, 372(1):208-220.

doi:10.1186/1471-2164-11-183

Cite this article as: Castorena et al:: Complementary transcriptomic lipidomic, and targeted functional genetic analyses in cultured Drosophila cells highlight the role of glycerophospholipid metabolism in Flock House virus RNA replication. BMC Genomics 2010 11:183.

\section{Submit your next manuscript to BioMed Central and take full advantage of:}

- Convenient online submission

- Thorough peer review

- No space constraints or color figure charges

- Immediate publication on acceptance

- Inclusion in PubMed, CAS, Scopus and Google Scholar

- Research which is freely available for redistribution

Submit your manuscript at www.biomedcentral.com/submit
Biomed Central 